\title{
El inicio de la emergencia en los Andes del norte: una perspectiva a partir del registro tectónico-sedimentológico del Coniaciano al Paleoceno
}

\author{
ㄱ) Germán Bayona \\ Corporación Geológica ARES, Bogotá, D.C., Colombia \\ Artículo de posesión para el ingreso como miembro correspondiente a la \\ Academia Colombiana de Ciencias Exactas, Físicas y Naturales el 21 de noviembre de 2018
}

\begin{abstract}
Resumen
El norte de los Andes está conformado por varias cadenas montañosas y extensos drenajes que transportan sedimentos a los océanos circundantes. La configuración actual no representa la de los primeros estadios de formación de los Andes del norte. La integración de la información sedimentológica, estratigráfica, geocronológica y de la procedencia de unidades del Coniaciano al Paleoceno expuestas al oriente de la Cordillera Central permite interpretar el cambio en los sistemas de acumulación de ambientes marinos de plataforma a sistemas continentales fluviales y planicies costeras, y establecer la ubicación de los primeros sistemas montañosos y los drenajes que suministraron sedimentos terrígenos a la cuenca. En el Campaniano temprano comenzó la aparición de bloques al occidente sobre la plataforma marina, en tanto que en el Campaniano tardío, emergieron altos intraplaca hacia el oriente, los cuales aumentaron el suministro de sedimentos terrígenos detríticos al sistema marginal y marino de la cuenca. Los altos intraplaca orientales y el sistema marginal occidental crecieron hacia el norte durante el Maastrichtiano-Paleoceno como producto de los procesos de colisión y acrecentamiento de los bloques alóctonos. Estos levantamientos dieron inicio a varios sistemas de drenaje que cubrieron desde las planicies continentales hasta las marginales adyacentes; sin embargo, la poca capacidad de transporte de sedimentos y la alta tasa de subsidencia favorecieron la acumulación de los sedimentos terrígenos gruesos en canales, planicies y deltas intracontinentales, y solo los sedimentos terrígenos lodosos llegaron a la línea de costa. Esta evolución de los sistemas montañosos y drenajes difiere de lo propuesto por estudios previos que sugieren el crecimiento de altos intraplaca desde el Paleoceno. (C) 2018. Acad. Colomb. Cienc. Ex. Fis. Nat.
\end{abstract}

Palabras clave: Andes del norte; Levantamiento; Sedimentología; Campaniano; Maastrichtiano; Paleoceno.

The onset of the mountain uplift in the northern Andes: A perspective based on Coniacian to Paleocene tectono-sedimentary studies

\begin{abstract}
Several mountain belts in the northern Andes are the source of sediments transported to adjacent oceans by extensive fluvial systems, but this present configuration does not correspond to the initial stages of the Andes growth. The integration of sedimentological, stratigraphic, geochronological and data provenance from the Coniancian to Paleocene strata exposed to the east of the Central Cordillera allow interpreting how depositional systems changed from marine to continental settings, and establishing the location of the first mountain belts and drainage systems that supplied terrigenous sediments into the basin. The onset of the emergence of blocks above a pre-existing middle-Cretaceous marine platform began in the early Campanian time to the west and in the late Campanian to the east, increasing the supply of terrigenous detrital sediments to the marginal and marine depositional systems. In the Maastrichtian to Paleocene time, several eastern intrabasinal uplifts and the western marginal mountain belt grew to the north, associated with the collision of allochthonous blocks along the northwestern corner of South America. Together with the growth of mountain belts, new drainage systems began to form and run into basins with high subsidence rates. Fluvial systems covered continental and marginal plains, but the low capacity of sediment transportation in these basins favored the accumulation of coarse terrigenous fragments in channels, floodplains, and inland deltas, whereas only muddy sediments arrived at the shoreline. This uplift evolution of mountain belts and drainage systems differ from previous studies that suggest the onset of intraplate deformation since the Paleocene time. (C) 2018. Acad. Colomb. Cienc. Ex. Fis. Nat.
\end{abstract}

Key words: Northern Andes; Uplift; Sedimentology; Campanian; Maastrichtian; Paleocene.

Correspondencia:

Germán Bayona, gbayona@cgares.org, Recibido: 12 de marzo de 2018, Aceptado: 7 de mayo de 2018, Editor: Carlos Jaramillo Muñoz 


\section{Introducción}

¿Dónde se localizaron y cómo crecieron las primeras montañas y drenajes sub-aéreos adyacentes en el norte de los Andes (Figura 1), y en qué momento comenzó la deformación andina? El objetivo de este manuscrito es responder a esta pregunta a partir del análisis sedimentológico, estratigráfico y de procedencia en las unidades litoestratigráficas que documentan el cambio de sistemas de la acumulación marina a continental en el norte de los Andes (Cooper, et al., 1995; Villamil, 1999). Diversos factores controlan el surgimiento de los drenajes en las montañas y las planicies sub-aéreas: pendiente del orógeno, erosión de la roca expuesta, área de drenaje en el sistema montañoso, conectividad de los drenajes, disponibilidad de fluido para erosionar y transportar sedimento, granulometría del sedimento transportado, estabilidad de los valles aluviales y crecimiento lateral y vertical de los sistemas de canales (Montgomery \& Dietrich, 1992; Schumm, et al., 2000). Montgomery \& Dietrich (1992) reportan una relación aproximada entre el área de drenaje y la longitud de la cuenca en donde corre el drenaje resultante (L): $\mathrm{L} \sim(3 \mathrm{~A})^{0,5}$.

La colisión entre placas tectónicas es uno de los mecanismos que deforma la corteza, dando inicio al levantamiento de cadenas montañosas en áreas donde antes se acumulaban sedimentos en cuencas marinas profundas. Estas montañas son la fuente de los primeros drenajes aéreos que luego produjeron el relleno de la cuenca oceánica con sedimentos detríticos terrígenos producto de la erosión de las nuevas cadenas montañosas, y formaron nuevas cuencas sedimentarias adyacentes a esas primeras montañas. El análisis del registro geológico de esas cuencas demuestra la emergencia de las montañas, que hoy están involucradas en la deformación reciente de las cordilleras o enterradas en el subsuelo, y permite dilucidar la composición de las montañas emergidas, la extensión geográfica de dichas montañas, la variación de los estilos de drenaje y la distancia del transporte de los sedimentos al sitio final de acumulación.

El estudio de la composición de los detritos terrígenos y de la orientación de los paleoflujos (es decir, las dunas de arena de fondo de canal), permite predecir en dónde estaban ubicadas esas nuevas cadenas montañosas que emergieron sobre una plataforma marina, en tanto que mediante el estudio sedimentológico de las rocas detríticas se determinan los procesos de erosión, transporte y acumulación de los sedimentos sobre la superficie terrestre. En este estudio se propuso el análisis sedimentológico y composicional de las rocas acumuladas entre el Coniaciano $(90 \mathrm{Ma})$ hasta finales del Paleoceno (56 Ma). Se seleccionó el Coniaciano como inicio de la evolución geológica descrita con base en los siguientes argumentos: 1) el nivel eustático global de primer orden estaba en su fase de máxima altura $(>200$ m) por encima del nivel del mar actual (Haq, 2014); 2) fue un periodo de muy baja generación de material detrítico terrígeno procedente de la margen oriental; 3) incluye los registros globales de los eventos anóxicos oceánicos del

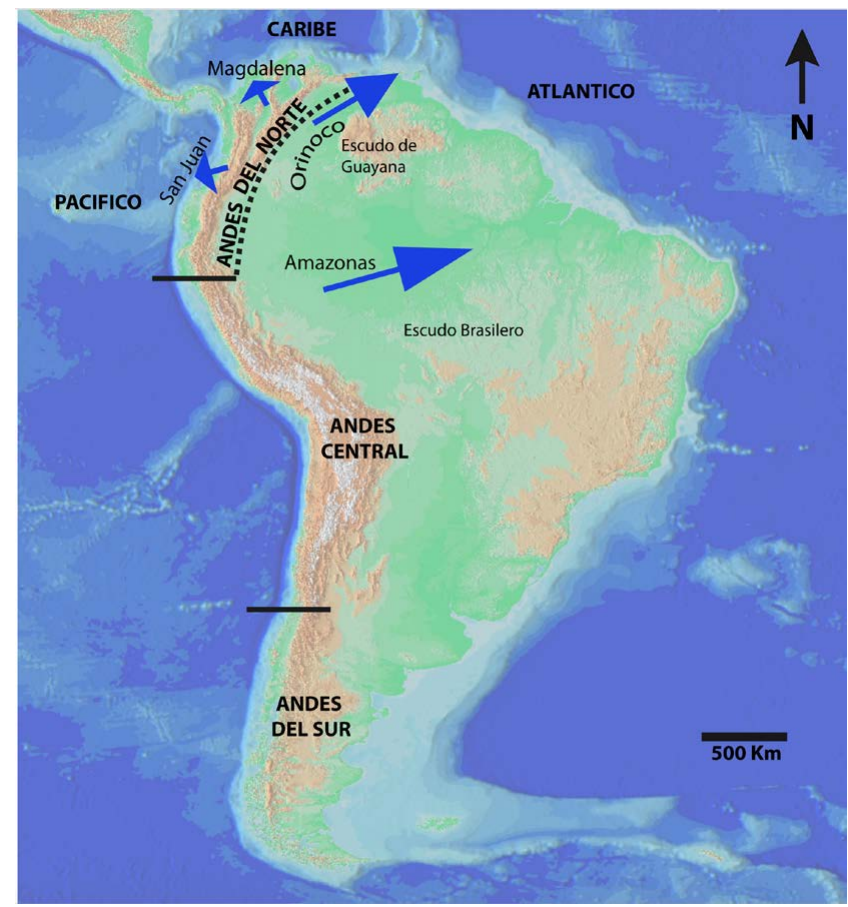

Figura 1. Expresión morfológica de la cadena montañosa de los Andes al occidente de la placa suramericana. En el sector norte de los Andes, la cordillera se abre en las tres cordilleras y hacia la margen sur del mar Caribe pasa a serranías aisladas (mapa base tomado de https://commons.wikimedia.org/wiki/File:Andes.png, Carlos A. Arango). Las flechas indican los drenajes principales que suministran sedimentos terrígenos a las cuencas marinas circundantes.

Coniaciano y Campaniano temprano (Hu, et al., 2012); 4) las rocas presentaban alto contenido fosilífero marino para su datación, y 5) la cuenca marina se desarrolló sobre una margen continental con muy baja actividad tectónica (Cooper, et al., 1995; Cediel, et al., 2003). En contraste, a finales del Paleoceno las cuencas sedimentarias existentes estaban totalmente colmatadas con sedimentos acumulados en ambientes continentales producto de una actividad tectónica de convergencia (Cooper, et al., 1995; Villamil, 1999; Bayona, et al., 2008, 2013; Ayala, et al., 2012; Reyes, et al., 2015).

La reconstrucción de estos primeros sistemas montañosos y sus drenajes tienen implicaciones en otras áreas de las ciencias naturales y en la economía de nuestro país. La generación de sistemas montañosos en áreas previamente cubiertas por océanos tiene efectos a nivel global debido a los cambios en la circulación de las corrientes marinas que desembocan en cambios climáticos globales. A escala más local, un nuevo sistema montañoso implica: 1) el inicio de procesos de erosión de la superficie, 2) la generación de sistemas de drenajes, 3) cambios de ecosistemas marinos a ecosistemas terrestres que se adaptan a diferentes topografías, 4) barreras para la migración de especies, y 5) cambios en las condiciones climáticas locales. En la exploración de hidrocarburos, la predicción de la extensión lateral de las 
unidades de reservorio requiere de un conocimiento del cambio de los reservorios acumulados en los fondos marinos a reservorios acumulados en los sistemas de canales. El avance de los sistemas de acumulación marginal a continental genera las condiciones favorables para la acumulación de turba, el material base del carbón. Las areniscas cuarzosas acumuladas en los fondos marinos y hacia los marginales en la parte oriental, hoy en día expuestas en la superficie, son la materia prima para la fabricación de vidrio. En la Sabana de Bogotá estas areniscas marinas cretácicas, así como las lodolitas rojas continentales, constituyen los materiales principales en la industria de la construcción.

\section{Marco geológico regional}

Los Andes son una cadena montañosa que se extiende por más de $8.500 \mathrm{kms}$ desde el extremo sur de Suramérica hasta la margen sur del Caribe colombiano y venezolano (Figura 1). En el sur de Colombia los Andes se dividen en tres cordilleras, y hacia el norte, cerca de la margen sur del Caribe colombiano y venezolano, comienzan a separarse en serranías de variada magnitud y orientación. Este complejo sistema montañoso es una barrera topográfica de escala continental y es la fuente de suministro de sedimentos detríticos a los drenajes que cubren la extensa placa suramericana hacia el oriente (por ejemplo, los ríos Amazonas y Orinoco), hacia el norte (el río Magdalena), o al occidente (el Río San Juan) (Figura 1). Esta configuración de extensos drenajes y cadenas montañosas es el reflejo de la colisión entre varias placas oceánicas en el oeste con la placa continental suramericana en los últimos $10 \mathrm{Ma}$ (Hoorn, et al., 1995; Mora, et al., 2015; Anderson, et al., 2016; Horton, et al., 2018), y el inicio de la emergencia de los Andes a nivel regional comenzó a finales del Cretácico (ca. 66-70 Ma; ver revisión en Horton, et al., 2018). A mediados del Cretácico (ca 85-90 Ma), el territorio que hoy ocupa el sector norte de los Andes y la cuenca de los Llanos orientales era ocupado por fondos oceánicos en donde se acumularon extensos depósitos producto de la precipitación química en los océanos (Erlich, et al., 2003; Pindell \& Kennan, 2009). Las áreas expuestas que servían de fuente y suministraban sedimentos detríticos a la cuenca marina cretácica estaban localizadas en el sector más oriental de la cuenca de los Llanos, que incluye rocas sedimentarias del Paleozoico y rocas ígneas y metamórficas de la edad Precámbrica (Escudo de Guayana en la Figura1).

Las características de los procesos tectónicos de convergencia en la esquina noroccidental de Suramérica son un tema de controversia debido a la colisión y los acrecentamientos de bloques de las cortezas continental y oceánica (Spikings, et al., 2015; Jaramillo, et al., 2017), al cambio de la orientación de la convergencia (Cortés, et al., 2005) y el ángulo de subducción (Bayona, et al., 2012) a lo largo de una margen continental curva, y al origen (autóctono o en el Pacífico) y la composición de los bloques oceánicos al occidente, que se supone que fueron acrecentados (Pindell, et al., 2006).
El conocimiento de los sistemas de acumulación del Cretácico al Paleógeno al occidente de la cordillera Central, los procesos de acrecentamiento de bloques y los cambios en los procesos de subducción (velocidad, polaridad y angularidad) en la margen occidental son procesos que condicionaron la conformación de las cadenas montañosas occidentales en el norte de los Andes (Villagómez \& Spikings, 2013; Jaramillo, et al., 2017). La correlación de los depósitos sedimentarios cretácicos y paleocenos al occidente de la cordillera Central ameritan una mayor atención y discusión en el futuro, pero no son el objeto de este manuscrito.

\section{Modelo conceptual}

Los cambios en la acumulación de los fondos marinos de precipitación química a fondos marinos de acumulación terrígena, que pasan de fondos de acumulación en condiciones marginales a condiciones continentales, quedan registrados en columnas estratigráficas que ilustran la aparición de la sedimentación clástica de origen terrígeno y el aumento de la granulometría de los detritos hacia el tope del registro estratigráfico (sucesión granocreciente). Dos secciones estratigráficas de referencia (Figura 2) ilustran los cambios en los sistemas de acumulación con respecto a la distancia del lugar donde ocurre la emergencia de los sistemas montañosos. La columna de referencia del sector proximal presenta un sistema de carbonatos en la base (sedimentación marina por procesos químicos), que pasan a ser sistemas clásticos detríticos finos de plataforma, y en el tope, conglomerados y paleosuelos acumulados en sistemas de abanicos fluviales; estos últimos son el registro de la cercanía de los sistemas montañosos. La columna estratigráfica de referencia del sector distal presenta rocas de carbonatos marinos en la base, que pasan de ser sistemas clásticos detríticos lodosos a arenosos de plataforma marina somera, y en el tope incluyen estratos de areniscas y lodolitas acumulados en sistemas marginales a continentales. En las zonas más apartadas de los altos topográficos, la acumulación de los detritos terrígenos controla el proceso de migración de la línea de la costa y la ampliación de las condiciones de acumulación en sistemas marginales. La abundancia de vegetación en estas zonas queda registrada por la acumulación de turba, que es la materia base del carbón. Los depósitos marginales a continentales incluyen el mejor registro palinológico (fundamental para el control de la edad de acumulación), en tanto que en las sucesiones más proximales a los altos topográficos, este registro fósil se pierde por procesos de meteorización.

La termocronología ha sido una de las tecnologías más socorridas en el estudio de la construcción de los sistemas montañosos. En el contexto de este estudio, esta técnica no era aplicable para determinar la temporalidad del inicio de los procesos de denudación, en especial de los primeros kilómetros. La termocronología establece el proceso de enfriamiento de una roca entre las isotermas $550{ }^{\circ} \mathrm{C}$ a 60 $40{ }^{\circ} \mathrm{C}$ (es decir, la exhumación) (Villagómez \& Spikings, 

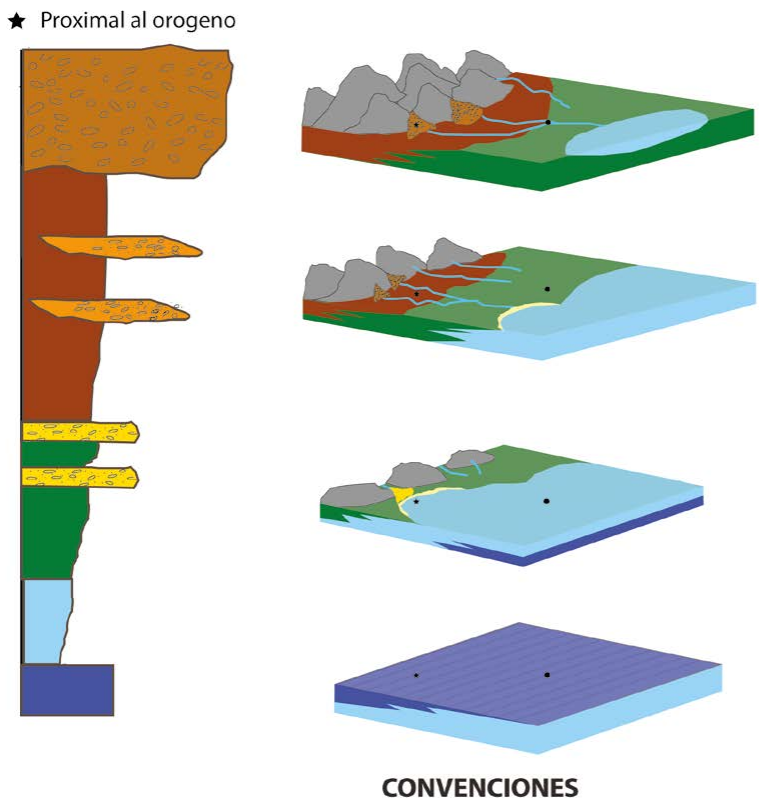

- Distal al orogeno

Plataforma marina a marginal
$\square$ Carbonatos
Marino
$\square$ Siliciclástico arenoso
Siliciclástico arcillo-limoso
Siliciclástico lodoso -
chert y carbonatos

Figura 2. Modelo conceptual del registro sedimentario que permite reconocer la emergencia de un sistema montañoso en una localidad próxima al orógeno y en otra localidad ubicada en una zona distal al sistema montañoso. Las sucesiones sedimentarias en ambos casos son granocrecientes y la escala vertical puede alcanzar varias centenas de metros. Se trata de un bloque de diagrama sin escala, pero refleja el crecimiento de un sistema montañoso. Los canales que no llegan a la línea de costa por la baja capacidad de transporte de sedimentos generan deltas intracontinentales.

2013). Por consiguiente, la erosión de los primeros $2 \mathrm{~km}$ no se detecta con esta técnica, pero sí queda registrada por el aporte de sedimentos terrígenos detríticos a la cuenca sedimentaria adyacente. Sin embargo, la termocronología es la técnica apropiada para determinar las variaciones en las tasas de los procesos de enfriamiento de una roca (es decir, la exhumación) en los sistemas montañosos después de su aparición, como se ha documentado para la cordillera Central desde el Campaniano tardío (Villagómez \& Spikings, 2013) y para la cordillera Oriental desde el Paleoceno (Parra, et al., 2012) y el Eoceno-Oligoceno (Mora, et al., 2013; 2015).

\section{Metodología y fuente de información}

Este manuscrito integra información geocronológica, estratigráfica, sedimentológica y de procedencia en 29 localidades ubicadas entre la cordillera Central y el Macizo de Santa Marta y las cuencas de los Llanos y de Maracaibo. Se construyeron tres líneas de correlación regional con dirección sur-norte en la posición geográfica actual (Figura 3A) usando la carta cronoestratigráfica internacional de Cohen, et al. (2013, actualizada en el 2017), la curva de eustasia de Haq (2014) y la base de restauración palinspástica para el Paleoceno de Bayona, et al. (2012) y Cardona, et al. (2014) (Figura 3B). Los estudios compilados en cada localidad (Figura 4) reportaron la definición de las unidades estratigráficas diferenciadas entre el Coniaciano y el Paleoceno, la interpretación de los ambientes sedimentarios de cada unidad y las edades según diferentes métodos de datación por macrofósiles (amonitas), microfósiles (foraminíferos, dinoflagelados, palinología) y dataciones con uranio y plomo $(\mathrm{U} / \mathrm{Pb})$ del material de origen volcánico (bentonitas y zircones volcánicos). Mediante las unidades estratigráficas con rango de dataciones muy amplio (por ejemplo, Coniaciano a Maastrichtiano y Paleoceno), se hizo la correlación determinando aquellas que incluían los dos eventos regionales de inundación máxima en el Cretácico tardío (TuronianoConiaciano y Campaniano) (Haq, 2014), o las relaciones de disconformidad en las unidades del Paleoceno.

Como resultado de esta compilación, se generaron las tres correlaciones crono-estratigráficas (visualización de la roca en un esquema espacial y temporal) mediante la interpretación de los ambientes de acumulación de los estratos aparecidos entre el Coniaciano y el Paleoceno. En estas tres correlaciones se detectaron los intervalos de tiempo con registro sedimentológico discontinuo, ya sea 

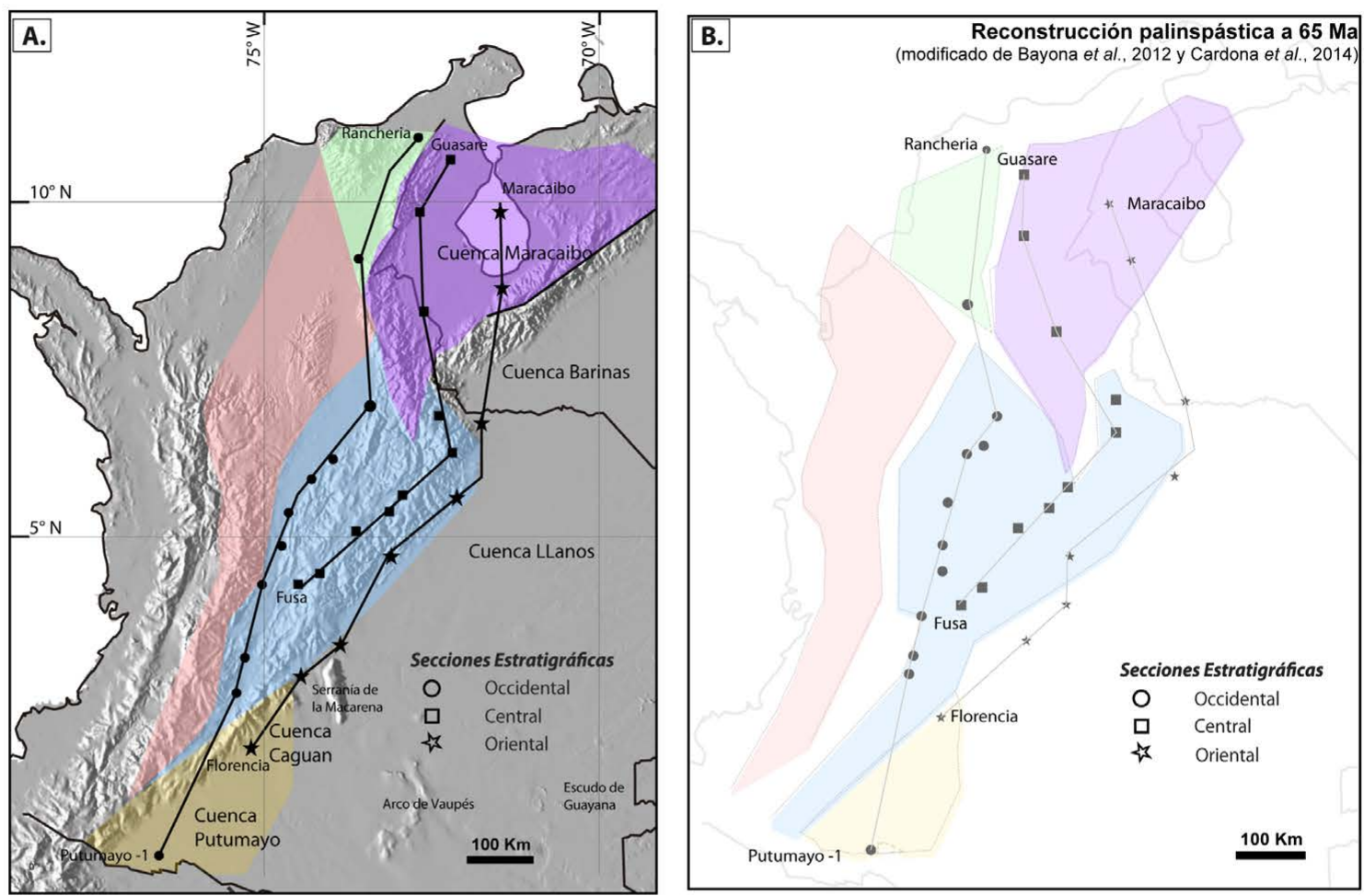

Figura 3. Ubicación de las 29 secciones estratigráficas y las tres líneas de correlación cronoestratigráfica en posición geográfica actual (A) y en posición palinspástica a $65 \mathrm{Ma}(\mathbf{B})$.

por no acumulación o por la posterior erosión (Figura 4). En la localidad 25 (Medina), se evidencia la complejidad de las relaciones estratigráficas dentro de la misma localidad debido al truncamiento a diferentes niveles estratigráficos (discordancias) producido por los eventos de deformación que aquí se presentan. Estas correlaciones fueron la base para la elaboración de los mapas paleogeográficos que se discuten a continuación.

\section{Configuración paleogeográfica del Conianiano al Santoniano}

La línea de costa en la margen noroccidental de Suramérica se localiza en el sector más oriental de la cuenca (Figura 5A); la acumulación en fondos marinos cubre los depósitos Paleozoicos antes expuestos y alcanza los límites del Escudo de Guayana (Etayo, et al., 1976; Villamil, 1999; SarmientoRojas, 2011). Hacia el extremo occidental se desarrollaron arcos de islas volcánicos sobre bloques de corteza mixta (Jaramillo, et al., 2017), los cuales se acrecentaron posteriormente en la margen continental. No hay evidencia de actividad magmática del Coniaciano-Santoniano en la margen continental, la cual cesó en el Cretácico temprano (Bustamante, et al., 2016).

Esta configuración paleogeográfica representa la máxima extensión de una cuenca cretácica marina sin presencia de bloques de corteza continental emergidos al occidente (Erlich, et al., 2003) (Figura 5A). En todas las secciones estratigráficas analizadas se documentó la acumulación en condiciones anóxicas de shales negros en la línea de correlación oriental. En la parte más distal de la plataforma se registraron liditas y cherts e, inclusive, intervalos condensados donde la tasa de acumulación fue muy baja o no se registraron (Martínez \& Hernández, 1992; Patarroyo, et al., 2017). Debido a la lejanía de la única fuente de sedimentos hacia el oriente en el Escudo de Guayana, con exposición de rocas ígneas en pendientes muy bajas y con profundo desarrollo de paleosuelos, se registra una disminución drástica en el suministro de sedimentos terrígenos detríticos a la cuenca. El único registro del suministro de material procedente de los arcos de islas occidentales desde el Cenomaniano lo constituyen las delgadas capas de ceniza volcánica (Villamil \& Arango, 1998; Ballesteros, et al., 2013).

\section{Configuración paleogeográfica del Campaniano temprano}

En la línea de correlación oriental y central, las sucesiones granocrecientes del Campaniano inferior (78-83 Ma) son producto de las fluctuaciones eustáticas, y registran episodios de regresión normal y de transgresiones de la línea de costa. En la línea de correlación occidental se observó el primer registro de acumulación de sedimentos terrígenos arenosos en fondos marinos someros, pero con clara procedencia de sistemas emergentes hacia el occidente (Guerrero, et al., 2002; Montes, et al., 2003) (Figura 5B). Estos bloques emergidos occidentales son el producto de los procesos de subducción de la placa del pacífico (Jaramillo, et al., 2017). 


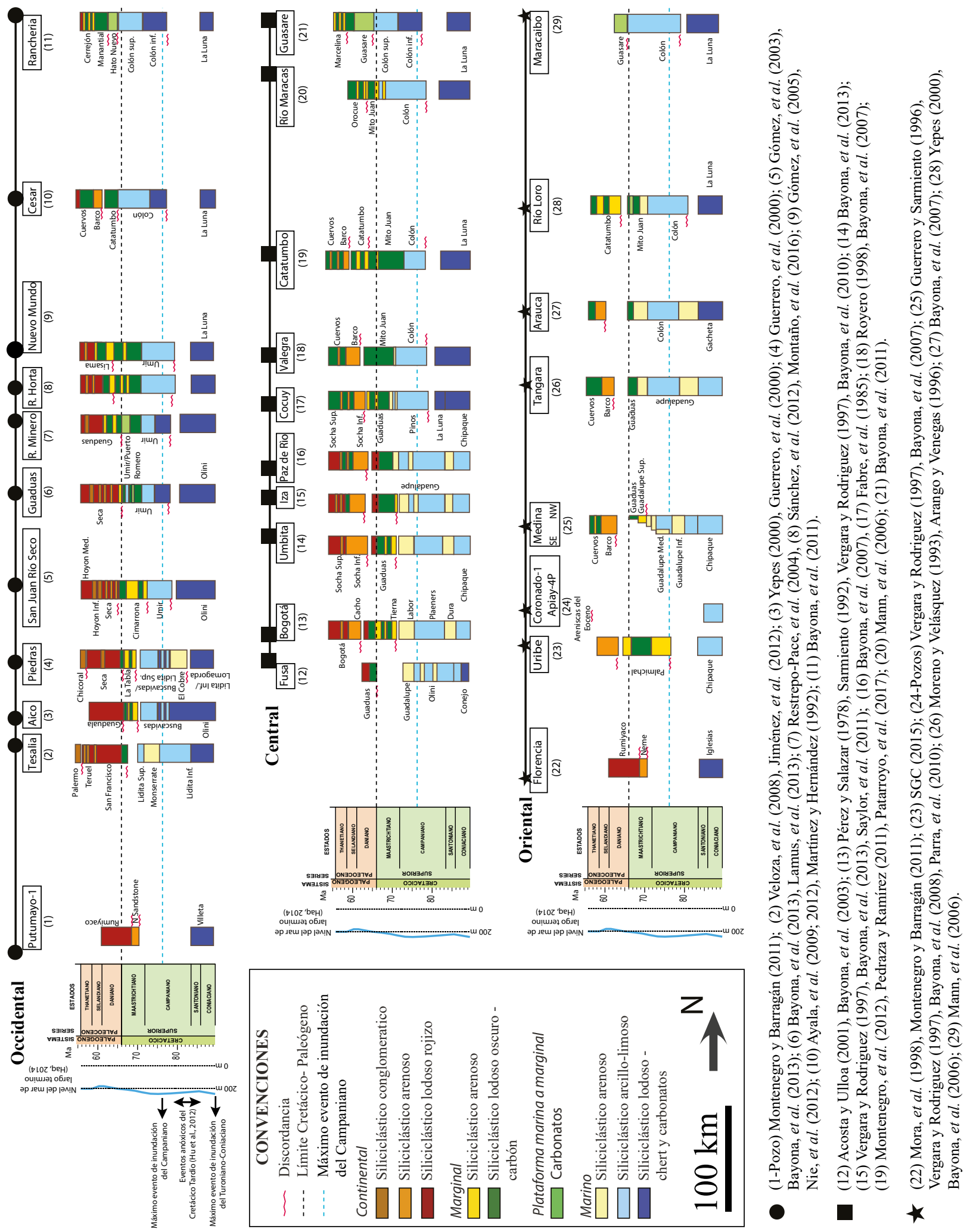

Figura 4. Correlación cronoestratigráfica a lo largo de las tres líneas de control ilustradas en la Figura 3. El nombre de las unidades litológicas excluye los términos de la nomenclatura litoestratigráfica (miembro, formación, grupo) para facilitar la lectura (ver referencias de cada localidad para el uso adecuado de la nomenclatura). Escala de tiempo tomada de Cohen, et al. (2013, actualizado a 2018). Dos líneas de tiempo a $66 \mathrm{Ma}$ (límite Cretácico-Paleógeno) y 76 Ma (máximo evento de inundación del Campaniano) se usaron con líneas de referencia que facilitan la lectura de correlación. 

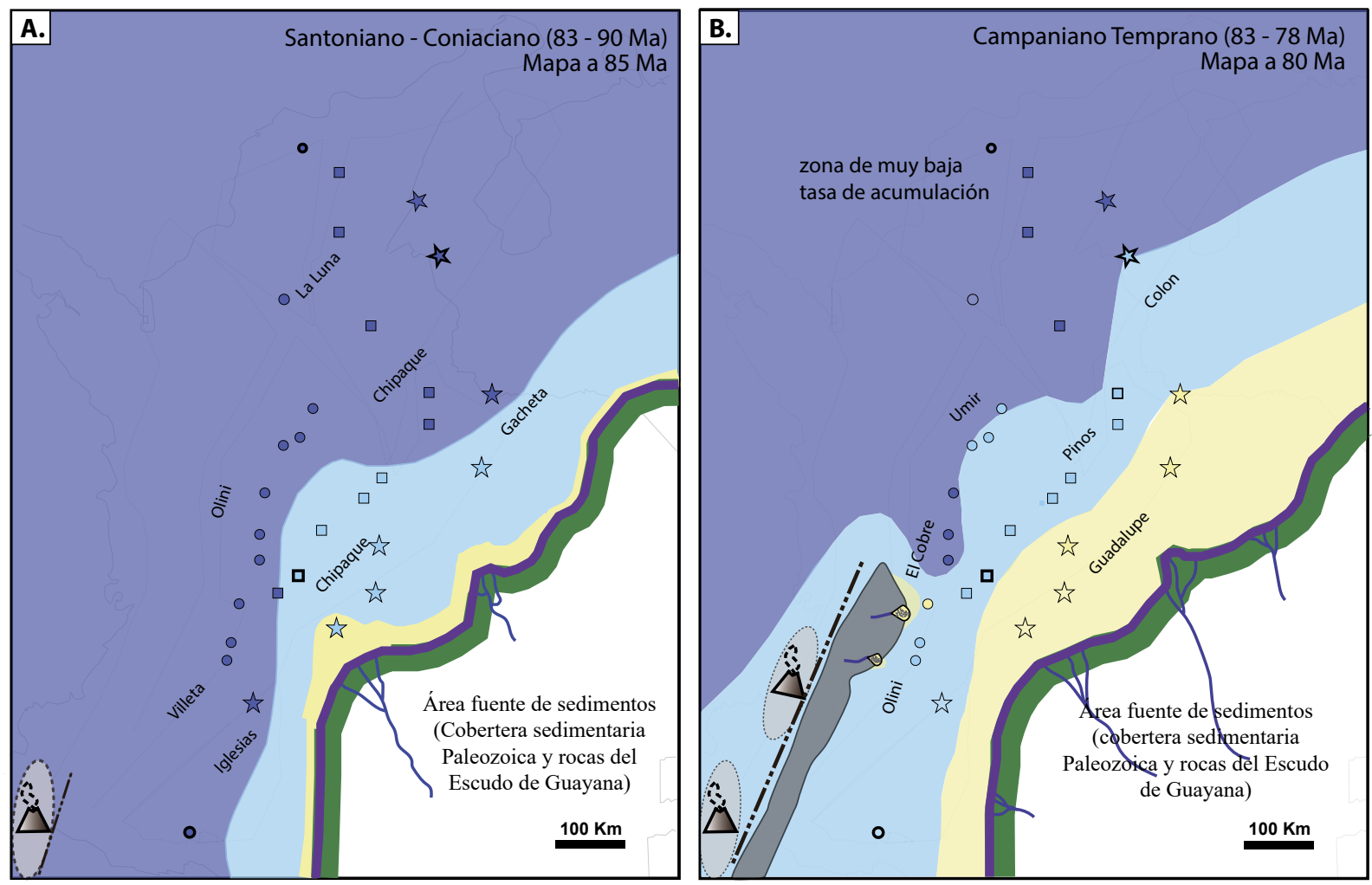

\begin{tabular}{|c|c|c|c|}
\hline 芯 & Volcán & \multicolumn{2}{|c|}{ Ambientes de acumulación } \\
\hline & Linea de costa & $\square$ Registro erodado o no registro & Plataforma somera a marginal \\
\hline & Sutura entre bloques acrecentados & Continental & $\square$ Carbonatos \\
\hline & y límite de placa continental & $\square$ Siliciclástico conglomeratico & Marino \\
\hline & Bloques acrecentado & $\square$ Siliciclástico arenoso & $\square$ Siliciclástico arenoso \\
\hline & Bloques emeraentes de & $\square$ Siliciclástico lodoso rojizo & $\square$ Siliciclástico arcillo-limoso \\
\hline & occidental (cobertera sedimentaria y & Marginal & $\square$ Siliciclástico lodoso - chert y carbonatos \\
\hline & basamento C. Central - Macizo Santa Marta) & $\square$ Siliciclástico arenoso & Secciones Estratigráficas \\
\hline$\because \because$ & $\begin{array}{l}\text { Bloques emergentes intraplaca (cobertera } \\
\text { sedimentaria y basamento Grenvilliano) }\end{array}$ & $\begin{array}{l}\square \text { Siliciclástico lodoso oscuro - carbones } \\
\text { canales } \quad \text { pantanos, ciénagas }\end{array}$ & O Occidental $\square$ Central Oriental \\
\hline
\end{tabular}

Figura 5. Mapas paleogeográficos para el (A) Santoniano-Coniaciano y (B) Campaniano temprano. Nótese el inicio de la emergencia del sistema montañoso marginal hacia el suroccidente relacionado con la colisión de bloques alóctonos.

El aumento del suministro de sedimentos terrígenos finos procedentes de dos fuentes localizadas al oriente y al occidente (Figura 5B) generó cambios en los procesos de acumulación, pasando de precipitación química a sedimentación detrítica fina (arcillas). Este contacto posiblemente corresponde a una discordancia recientemente denominada xenoconformidad (Carroll, 2017). En los extremos norte y occidental de la plataforma, donde la acumulación por precipitación química aún puede persistir, se tiene el registro de una sección condensada (Martínez \& Hernández, 1992).

\section{Configuración paleogeográfica del Campaniano tardío}

El inicio de la disminución del nivel eustático global hacia cerca de los $75 \mathrm{Ma}$ (Haq, 2014) marca el registro del último sistema progradante de una antigua margen pasiva, la cual se vió afectada por el desarrollo de bloques emergidos en los dos bordes del sur de la cuenca (Figura 6A). En el sector sur de la línea de correlación oriental, correspondiente al piedemonte Llanero sur, las sucesiones granocrecientes se reportan tanto en La Uribe (Servicio Geológico Colombiano - SGC, 2015) como en la sección de Medina (Guerrero \& Sarmiento, 1996; Vergara \& Rodríguez, 1997). Esto implica cambios en la configuración de la morfología de las áreas emergidas al sur de la Sierra de La Macarena, que generaron una topografía apta para el aumento del suministro de los sedimentos arenosos clásticos hacia el norte e, inclusive, el inicio de la erosión al sur de La Macarena en las cuencas de Caguán y Putumayo (Figuras 3 y 6A).

En la línea de correlación central, el incremento en el suministro de sedimentos detríticos gruesos procedentes de las nuevas zonas emergidas al sur de La Macarena, se 

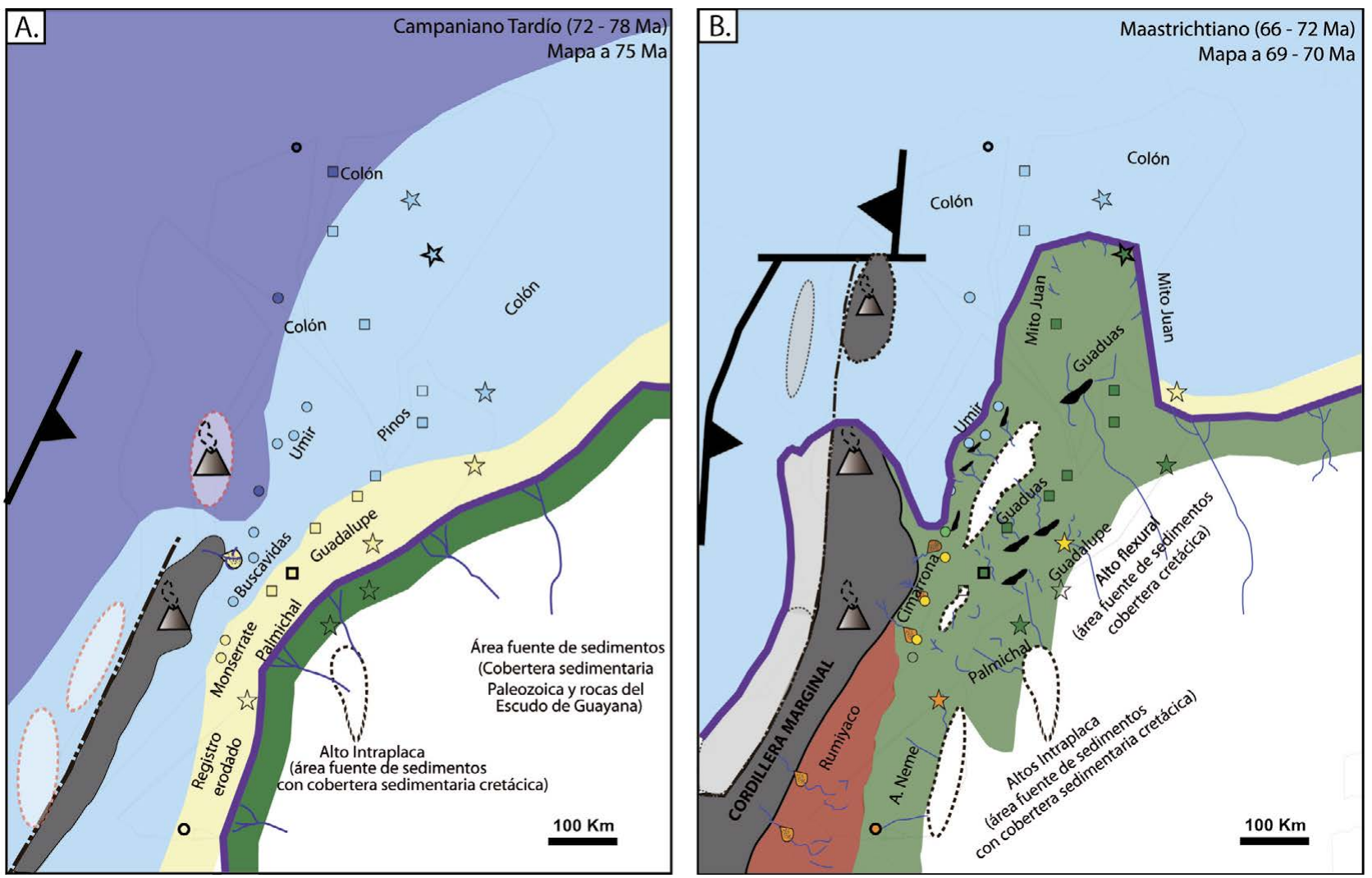

Figura 6. Mapas paleogeográficos para el (A) Campaniano tardío y (B) Maastrichtiano. Nótense los levantamientos intraplaca de sur a norte, similares al patrón de crecimiento de la cordillera marginal al occidente. El retiro acentuado hacia el norte de la línea de costa durante el Maastrichtiano es producto del incremento en el suministro de sedimentos terrígenos procedentes de varias fuentes. Ver la leyenda y el texto de la Figura 5 para la discusión

registra por la acumulación de la Formación Arenisca Tierna, unidad del tope del Grupo Guadalupe (Díaz, 1994; Vergara \& Rodríguez, 1997; Veloza, et al., 2008). Este proceso de regresión forzada generó un contacto disconforme con las areniscas infrayacentes del Grupo Guadalupe. Hacia el norte, el registro sedimentario es detrítico, pero de granulometría fina. La acumulación de carbonatos y cherts en los fondos marinos se restringe a las zonas más distales de la línea de costa.

Al suroccidente, el crecimiento de sistemas montañosos queda registrado por las sucesiones granocrecientes en la Formación Cimarrona, acumuladas en sistemas de abanicos deltaicos (Gómez, et al., 2003). Sin embargo, estos sistemas terrígenos son locales (Gómez, et al., 2003), lo que permite la acumulación de carbonatos a pocas decenas de kilómetros del delta y la acumulación de lodolitas de fondos marinos producto de leves transgresiones marinas (Guerrero, et al., 2000; Restrepo-Pace, et al., 2004), lo cual implica que el sistema de drenaje aún no capturaba suficientes sedimentos para dispersarlos hacia la cuenca.

\section{Configuración paleogeográfica del Maastrichtiano}

Durante el Maastrichtiano se reporta la emergencia regional de los Andes de Ecuador (Horton, et al., 2018). En nuestra zona de estudio, la emergencia de bloques comienza a obtener un relieve más continuo en las dos márgenes hacia el sur, generando una mayor producción de sedimentos detríticos (Figura 6B). El registro de las areniscas cuarzosas del Neme y las "areniscas N" en las secciones de Florencia y Putumayo, respectivamente, son producto de la erosión de los altos desarrollados al oriente de la línea de correlación oriental, que inclusive se desarrollaron al norte de La Macarena, como lo indica la ausencia de registro del Campaniano y Masstrichtiano en los pozos Coronado-1 y Apiay 4P (Figura 4). Las areniscas y conglomerados en el tope del Grupo Guadalupe, en las secciones del piedemonte llanero, y de Bogotá hasta Paz del Río, registran el avance de la acumulación de los sedimentos terrígenos procedentes de estos altos surorientales. La caída global del nivel eustático favoreció la retirada regional del nivel del mar (Haq, 2014), pero el alto suministro de sedimentos terrígenos fue el que controló la nueva posición de la línea de costa hacia el norte de la cuenca (Figura 6B).

En el sur y en el centro de la línea de correlación occidental, los sedimentos arenosos-conglomeráticos de las unidades La Tabla y Cimarrona y las capas de las unidades con carbonatos hacia el norte quedaron totalmente sepultadas por lodolitas y areniscas acumuladas en sistemas de llanuras 
costeras a continentales de la Formación Seca. Las litologías $\mathrm{y}$ asociaciones de palinofacies reportadas en esta última unidad (Guerrero, et al., 2000; Bayona, et al., 2013) indican una acumulación en ambientes continentales, lo que evidencia el desarrollo de relieves continuos emergidos al occidente denominados como cordillera marginal (Figura 6B).

A finales del Maastrichtiano, el material terrígeno colmató las cuencas sedimentarias continentales a marginales, como se evidencia en el dominio de sucesiones finas de paleosuelos en los sectores sur de las tres líneas de correlación, que hacia el norte pasan a sucesiones finas y arenosas acumuladas en ambientes marginales. La generación de suelos y la exposición de rocas sedimentarias de litología fina son la fuente primaria del material lodoso. Lo anterior permite sugerir el inicio del levantamiento de altos intraplaca, los cuales también quedaron cubiertos por una extensa cobertera vegetal.

Las extensas llanuras marginales y los pocos canales que las cortan permiten el registro de la turba, material base para la formación de los mantos de carbón presentes en las formaciones Guaduas y Umir. Al norte y occidente de la línea de costa, los únicos sedimentos detríticos que llegaron a los fondos marinos fueron partículas lodosas, lo que generó un registro uniforme de las lodolitas laminadas oscuras de la Formación Colón.
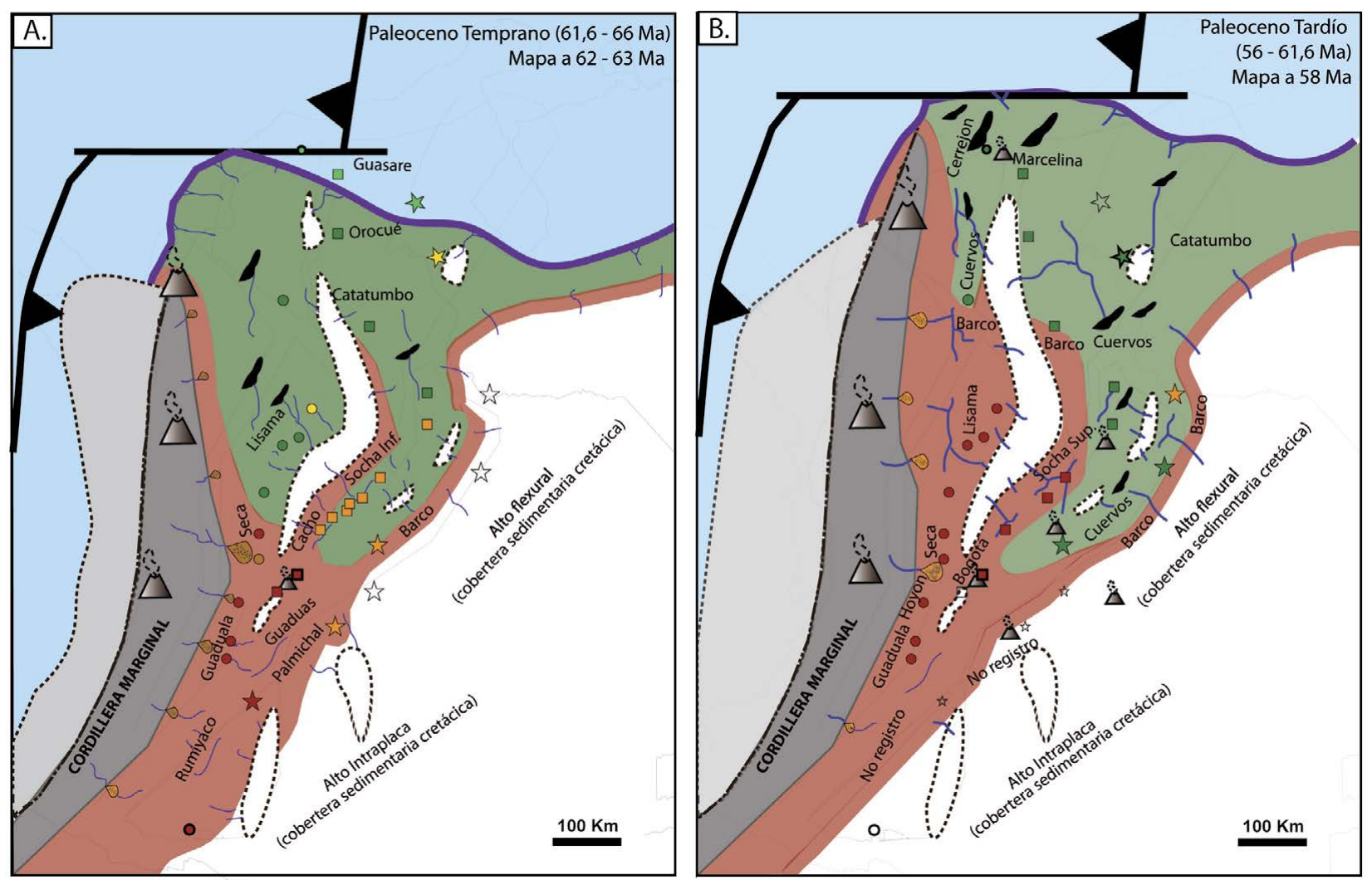

Figura 7. Mapas paleogeográficos para el (A) Paleoceno temprano y (B) Paleoceno tardío. Nótese el dominio en la acumulación en sistemas sedimentarios continentales a marginales, la presencia de varios bloques intraplaca emergidos y la migración de la actividad volcánica hacia el oriente. Ver la leyenda y el texto de la Figura 5 para la discusión
La ausencia de partículas arenosas en los fondos de acumulación marina indica un estado inmaduro de los drenajes continentales. La alta subsidencia debido a la tectónica activa de estas cuencas favoreció el desarrollo de deltas intracontinentales, en donde los canales se desvanecieron en largas planicies marginales y no hubo capacidad de transporte de los detritos gruesos a la línea costera. Los episodios de ingresiones marinas ocupan ampliamente estas llanuras marginales (Sarmiento, 1992; Montaño, et al., 2016), y se 'retrabajaron' los sedimentos acumulados previamente sobre las planicies y los deltas intracontinentales.

\section{Configuración paleogeográfica del Paleoceno temprano}

Por la línea de correlación occidental hacia el suroccidente, las extensas llanuras continentales con canales aislados y desarrollo de paleosuelos (Rumiyaco, Guaduala, Seca) registran la erosión del sector sur de la cordillera marginal (Figura 7A). Hacia el norte, los sistemas de drenaje fluvial que se formaron fueron someros e intermitentes, y cortaron los sistemas marginales de llanuras costeras al tope de la Formación Umir. Estos sistemas de drenaje maduraron y quedaron registrados en la Formación Lisama como areniscas acumuladas en sistemas de canales fluviales amalgamados. En el sector más norte, los sistemas de acumulación 
marginal (formaciones Manantial y Orocué) cubrieron los depósitos de plataforma de carbonatos existentes (formaciones Hato Nuevo y Guasare) (Figura 7A). Esta distribución de ambientes permite inferir la extensión hacia el norte de la cordillera marginal al occidente, la cual fue acompañada por el crecimiento de un arco magmático producto de la subducción de la placa del Caribe (Bayona, et al., 2012; Bustamante, et al., 2017). Sin embargo, los detritos llegaron a llanuras extensas y no generaron sistemas fluviales maduros que transportaran sedimentos detríticos gruesos hasta la línea de costa.

La subducción de la placa Caribe en la margen occidental en el Paleoceno mantuvo activos los altos intraplaca al suroriente y generó nuevos sistemas montañosos intraplaca hacia el norte. Estos nuevos altos aumentaron el suministro de sedimentos terrígenos arenosos cuarzosos debido a la erosión de las coberteras sedimentarias cuarzosas del Cretácico Superior (Bayona, et al., 2013). Las extensas sabanas de areniscas de canales trenzados y amalgamados de las formaciones Cacho y Socha Inferior son el registro de los sistemas de canales fluviales que se formaron alrededor de estos altos intraplaca. Aunque el incremento de los sistemas montañosos intraplaca aumenta el poder de transporte en los sistemas de drenaje previos, la alta tasa de subsidencia en la cuenca no permitió la conectividad de los sistemas de drenajes (Bayona, et al., 2013. Los altos intraplaca deformaron por flexión la corteza hacia el oriente, y generan, así, un alto de flexión (Figura 7A), el cual expuso en la superficie rocas cuarzosas del Cretácico Superior, convirtiéndose en la roca fuente de los detritos cuarzosos de la Formación Barco en la región del piedemonte llanero (Bayona, et al., 2007).

Hacia el norte la cuenca rota por los altos intraplaca, que involucran el basamento metamórfico del Macizo de Santander y los bloques en los Andes de Mérida, suministraron sedimentos detríticos tanto a las cuencas del Valle medio del Magdalena (Formación Lisama) y Cesar (Formación Barco), como a las cuencas del Catatumbo y sur de Maracaibo (Formación Catatumbo). Sin embargo, los drenajes procedentes de estos altos tuvieron un poder limitado de transporte de sedimentos. La fracción arenosa quedó acumulada en las proximidades de los altos y fueron los sedimentos lodosos los que colmataron la cuenca y generaron el retiro de la línea de costa a su sector más norte. El suministro de detritos terrígenos al norte y occidente de la línea costera fue limitado, lo que permitió la acumulación de carbonatos al norte (formaciones Guasare y Hato Nuevo), siendo éste el último registro de carbonatos marinos al norte de Suramérica (Bayona, et al., 2011).

\section{Configuración paleogeográfica del Paleoceno tardío}

La presencia de sistemas de abanicos aluviales registrados en el sector suroccidental de la cuenca indica la proximidad de altos topográficos con relieve significativo, y un sistema de drenajes que permitió el transporte de fragmentos del tamaño de la grava en su sistema de fluidos por varias decenas de kilómetros (Gómez, et al., 2003; Bayona, et al., 2013) (Figura 7B).

Hacia el oriente, los altos intraplaca tendieron a conectarse y la deformación se extendió más al oriente de los altos preexistentes en el Paleoceno temprano (Bayona, et al., 2012) (Figura 7B). La actividad magmática se incrementó en la Cordillera marginal en el Paleoceno tardío (Cardona, et al., 2011, 2014; Bustamante, et al., 2017). Las capas gruesas de cenizas volcánicas al sur de Bogotá (Bayona, et al., 2010) y al nororiente de Perijá (Bayona, et al., 2011) son el indicio de la actividad magmática intraplaca. La presencia de circones volcánicos y de abundantes fragmentos de rocas volcánicas en areniscas del Paleoceno superior entre las localidades de Iza y Paz del Río (Saylor, et al., 2011) puede interpretarse como evidencia de la actividad magmática intraplaca cuyos depósitos fueron erosionados. La deformación se extendió hasta la parte proximal de la cuenca de los Llanos (Mora, et al., 2013), donde se ha documentado la presencia de capas de tobas al tope de las unidades del Paleoceno (Bayona, et al., 2015).

A pesar de tener unos sistemas montañosos intraplaca maduros, el sistema de drenajes no tiene la capacidad para transportar los detritos arenosos en sistemas fluviales extensos. El Paleoceno tardío se caracterizó por el incremento en la tasa de subsidencia de las cuencas, un registro dominante de depósitos de llanuras continentales y marginales sobre los sistemas de canal, y el incremento en la inmadurez composicional de las areniscas (aumento de fragmentos de rocas metamórficas y volcánicas) comparadas con las del Paleoceno inferior. En el sector sur de la cuenca, la preservación de estos depósitos finos continentales se registra de manera deficiente debido a la subsecuente erosión causada por la acumulación de depósitos más gruesos del Paleoceno más superior y el Eoceno inferior. Por el contrario, hacia el norte, en las zonas de mayor subsidencia, los sistemas de canales quedan embebidos en el registro de las llanuras adyacentes. Al igual que en el Paleoceno temprano, los canales terminaron en sistemas deltaicos intracontinentales.

El avance regional de la deformación y el magmatismo hacia el oriente fue acompañado de una mayor acumulación en todas las cuencas sinorogénicas. Estos tres procesos (deformación, magmatismo, subsidencia), observados en todas las cuencas, estarían asociados a los procesos de subducción de la placa Caribe. El flujo del manto viscoso generado por esta subducción debajo la corteza continental de la placa Suramericana generó una fuerza de arrastre, en especial cuando la subducción fue de bajo ángulo (Mitrovica, et al., 1989; Gurnis, 1992). Este movimiento mantélico generó subsidencia a una escala de miles de kilómetros, afectando todas las cuencas sedimentarias (Catuneanu, 2018). En contraste, las cargas tectónicas y sedimentarias producen mayor deformación de la flexión de la corteza, provocando, a su vez, la migración al oriente de la línea de acumulación-erosión en la cuenca de antepaís de 
los Llanos, lo cual permite la acumulación de los sistemas de drenajes que proceden desde el alto de flexión al oriente, correspondiente a la Formación Barco, y en la zona de mayor subsidencia de flexión, la acumulación coetánea de las lodolitas y carbones de la Formación Cuervos (Bayona, et al0., 2007).

Hacia el norte de la cuenca, el levantamiento de la margen occidental del Macizo de Santa Marta, como parte norte de la cordillera marginal, y los altos intraplaca que incluyen los macizos de Santander y Floresta, fueron la fuente de los detritos del Paleoceno tardío con alto contenido de terrígenos de origen metamórfico (Bayona, et al., 2008, 2011; Ayala, et al., 2012; Saylor, et al., 2011). La alta subsidencia en estas cuencas permite tanto el registro de los sistemas de canales y llanuras marginales adjuntas, y también la espesa acumulación de turba que será el material base para las capas de carbón existentes en las cuencas de Catatumbo, Cesar, Ranchería y Guasare.

En resumen, en el Paleoceno tardío la Cordillera marginal y el arco magmático al occidente, así como los altos intraplaca, siguieron creciendo hacia el norte y oriente, conjuntamente con el desarrollo de nuevas fuentes volcánicas asociadas a la subducción de la placa Caribe.

\section{Discusión y conclusiones}

La emergencia de los sistemas montañosos en el norte de los Andes data del Campaniano temprano, y el registro sedimentológico de estos altos está incluido en las unidades arenosas locales acumuladas en fondos marinos someros al suroccidente. El registro sedimentológico del Maastrichtiano y Paleoceno en la línea de correlación occidental documenta el relleno de la cuenca marina con sedimentos terrígenos detríticos que se acumularon en fondos marinos que pasaron a ambientes marginales y terminaron en ambientes continentales; las unidades marginales y continentales hacia el norte son más jóvenes. Por consiguiente, si el sentido de relleno de la cuenca es sur-norte, se asume que la construcción de la topografía dominante de la cordillera marginal y de los altos intraplaca tiene el mismo sentido surnorte. Las altas tasas de exhumación reportadas en el sector central de la cordillera Central sustentan el crecimiento de la cordillera marginal en el Maastrichtiano (Villagómez \& Spikings, 2013); este sector central colinda con las localidades 4 y 5 , donde se registra el mayor contenido de sedimentos terrígenos (Figura 4).

$\mathrm{Al}$ norte de la margen continental existen otros procesos de colisión de bloques, como son los arcos de islas volcánicas formadas sobre la placa Caribe (Weber, et al., 2010), que desarrollaron topografías aisladas y no conectadas con la cordillera marginal. Asimismo, en el extremo norte se generaron altos intraplaca aislados, como el levantamiento del extremo norte de la Serranía de Perijá (Bayona, et al., 2011).

La dispersión de sedimentos terrígenos arenosos a conglomeráticos en la línea de correlación occidental fue muy local en sus primeras etapas de crecimiento (formaciones
El Cobre, La Tabla, Cimarrona) (Guerrero, et al., 2000; Gómez, et al., 2003), evidenciando los primeros estados de emergencia de la Cordillera marginal durante el Campaniano y Maastrichtiano. En el mismo sector suroccidental de la cuenca, las unidades del Paleoceno incluyen unidades muy espesas de conglomerados acumulados en sistemas de abanicos aluviales (Palermo, Chicoral, Hoyón inferior), lo que indica: 1) un estado más maduro de emergencia de la Cordillera marginal con un aumento de la topografía; 2) un incremento de las áreas de captación de sedimentos, y 3) el incremento en la capacidad de transportar los sedimentos a la cuenca a lo largo de drenajes más desarrollados.

A diferencia del avance hacia el norte del crecimiento de la cordillera marginal, la deformación de la margen suroriental de la cuenca Cretácica es relativamente estática; el registro más norte corresponde a la discordancia en los pozos Coronado-1 y Apiay-4P (Figura 4). Esta deformación se inició en el Campaniano tardío con el suministro de la fracción arenosa gruesa a los sistemas de acumulación marino somera y marginal de ese sector. El extenso esparcimiento de areniscas cuarzosas gruesas a conglomeráticas, correspondiente a la unidad arenosa en el tope del Grupo Guadalupe (Arenisca Tierna-Monserrate), indica una gran eficiencia en el transporte de detritos del drenaje suroriental, y de estos sedimentos terrígenos hacia el norte y oriente por corrientes marinas someras. El cambio abrupto a litologías lodosas en el Paleoceno temprano en este sector indica la disminución en la capacidad de transporte, o que los altos intraplaca obstruyeron el suministro de estos detritos. Los estudios de termocronología en los bloques surorientales serían fundamentales para determinar los procesos de exhumación de la margen suroriental de la cuenca cretácica.

Los altos intraplaca que separan las cuencas sinorogénicas se desarrollaron a partir del Maastrichtiano, y se extendieron y conectaron durante el Paleoceno. En el momento de emerger, estos bloques montañosos intraplaca tuvieron poco relieve en comparación con la cordillera marginal al occidente y la deformación de la margen suroriental de la cuenca cretácica. En los estudios de termocronología realizados en la cordillera Oriental (Mora, et al., 2013; 2015), en los Andes de Mérida (Bermúdez, et al., 2010) y en el Macizo de Santander (Van der Lelij, 2013), no se registran procesos de exhumación en el MaastrichtianoPaleoceno temprano, y solo en el trabajo de Parra, et al. (2012) se documentan procesos de exhumación en el flanco occidental de la cordillera Oriental en el Paleoceno tardío. La incompatibilidad en la temporalidad entre el registro sedimentario en las cuencas y la exhumación en los orógenos sustenta la hipótesis de una deformación de baja magnitud en estos altos intraplaca.

Dichos altos intraplaca, que separan cuencas sinorogénicas, suministraron sedimentos terrígenos arenosos e incrementaron la tasa de subsidencia en las cuencas adyacentes. Los sistemas de drenaje que surgían de estos altos intraplaca hacia las cuencas adyacentes no tenían la capacidad para el 
transporte de sedimentos. El registro de sistemas de canales embebidos en los depósitos de llanuras continentales y marginales documenta cómo estos canales terminaron rápidamente en las planicies de estas llanuras generando deltas intracontinentales. Ello implica una deficiente conexión de los sistemas de drenaje al interior de cada cuenca, y la ausencia de los drenajes dominantes axiales que permiten el transporte de los sedimentos arenosos hacia la línea de costa, lo cual se evidencia por el dominio de las litologías de tamaño de lodo y limo en los fondos marinos someros, y el registro de carbonatos en el Paleoceno.

Las rocas expuestas en los altos intraplaca difieren en composición a lo largo de rumbo. En los bloques sur domina la exposición de la cobertera sedimentaria cretácica cuarzosa, al igual que los altos del Campaniano-Paleoceno de la margen suroriental de la cuenca cretácica. Por consiguiente, la composición de los estratos arenosos en el Maastrichtiano y el Paleoceno inferior son cuarzosos. El registro en el Paleoceno inferior de areniscas cuarzosas acumuladas en canales trenzados obedece al incremento de la fluidez de los sistemas de drenaje. La gran fluidez en los drenajes es producto del incremento de gradiente y la ausencia de material lodoso en las áreas de fuente. Al incrementar la proporción de lodo en el sistema fluido, este disminuye su potencial y los canales cambian a sistemas de canales meandriformes, como se documenta en las unidades del Paleoceno superior.

La cobertera sedimentaria en los altos intraplaca norte y en la cordillera marginal tiende a ser lodosa y delgada. La rápida erosión de esta cobertera deja expuestas rocas ígneas y metamórficas de estos bloques, suministrando sedimentos composicionalmente muy inmaduros (fragmentos de rocas volcánicas y metamórficas), que constituyen la fracción que se incrementa en las rocas del Paleoceno inferior en el sector occidental, y en las del Paleoceno superior en las otras dos líneas de correlación.

La revisión de estos procesos de emergencia de bloques en el norte de los Andes difiere de lo propuesto en estudios previos, en los cuales se sugiere un avance hacia el oriente de la deformación iniciado a finales del Cretácico en el occidente y que culminó en el oriente en el Oligoceno (Reyes, et al., 2015; Horton, et al., 2018), ya que sus análisis se basan principalmente en estudios de termocronología.

\section{Agradecimientos}

Este estudio es producto de la compilación sistemática de información y observaciones personales realizadas en varias de las secciones con colegas de la Corporación Geológica ARES en estos últimos 25 años (el listado completo de colaboradores aparece en las publicaciones de Bayona, et al.). Los comentarios de Agustín Cardona y del editor Carlos Jaramillo ayudaron a mejorar el contenido de este manuscrito. Agradecemos a Camilo Montes por el continuo intercambio sobre la paleogeografía del norte de Sur América y los comentarios a las figuras de este manuscrito. Catalina Ramírez y Ana Salazar colaboraron en la construcción de las figuras de este manuscrito.

\section{Conflicto de intereses}

El autor declara no tener conflicto de intereses.

\section{Referencias}

Acosta, G.J. \& Ulloa, C. E. (2001). Geología de la plancha 246 Fusagasugá. Instituto de investigación e información geocientífica, minero-ambiental y nuclear - Ingeominas. Memoria explicativa, escala 1.100.000.

Anderson, V.J., Horton, B.K., Saylor, J.E., Mora, A., Tesón, E., Breecker, D.O., Ketcham, R.A. (2016). Andean topographic growth and basement uplift in southern Colombia: Implications for the evolution of the Magdalena, Orinoco and Amazon river systems: Geosphere. 12: 4. Doi: 10.1130/GES01294.1

Arango, F., Venegas, D. (1996). Análisis estratigráfico del Límite Cretácico Superior - Paleoceno en el bloque colgante de la falla de Guaicáramo, en alrededores de Támara, Casanare, VII Congreso Colombiano de Geología.

Ayala-Calvo, C., Bayona, G., Ojeda-Marulanda, C., Cardona, A., Valencia, V., Padrón, C., Yoris, F., Mesa-Salamanca, J., García, A. (2009). Estratigrafía y procedencia de las unidades comprendidas entre el Campaniano y el Paleógeno en la subcuenca de Cesar-Aportes a la evolución tectónica del área. Geología Colombiana. 34: 3-33.

Ayala-Calvo, C., Bayona, G., Cardona, A., Ojeda, C., Montenegro, O., Montes, C., Valencia, V., Jaramillo, C. (2012). The Paleogene synorogenic succession in the northwestern Maracaibo block: Tracking intraplate uplifts and changes in sediment-delivery systems. Special Edition on Tectonic and climatic shaping of the northern Andes and southern Caribbean margin (Edited by G. Bayona., B. Horton., A. Reyes-Harker). Journal of South America Earth Sciences. 39: 93-111.

Ballesteros, C.I., Galvis, H.A., Higuera, I.C., Marfisi, N.K., de la Parra, F., Céspedes, S., Cantisano, M.T., Forero, S.P., Barrera, P.A., Rodríguez, C.E., Zamora, W.H., Restrepo, D.P., Cerón, J., Castillo, R.D. (2013). Anotaciones acerca de la estratigrafía del intervalo Cenomaniano-Campaniano atravesado por el pozo La Luna-1, cuenca del Valle Medio del Magdalena. XVI Congreso Colombiano de Geología, Bogotá, p. 30-31.

Bayona, G., Cortés, M., Jaramillo, C., Llinás, R. (2003). The Fusagasugá succession: A record of the complex Latest Cretaceous-pre-Miocene deformation between the Magdalena Valley and Sabana de Bogotá areas. Asociación Colombiana de Geólogos y Geofísicos del Petróleo, Memorias del VIII Simposio Bolivariano de Cuencas Subandinas. 2: 180-193.

Bayona, G., Jaramillo, C., Reyes-Harker, A. (2006). Resultados paleomagnéticos en unidades del Paleógeno de Colombia y oeste de Venezuela y posibles usos para caracterización de contactos. Geología Colombiana. 31: 57-72.

Bayona, G., Jaramillo, C., Rueda, M., Reyes- Harker, A., Torres, V. (2007). Paleocene-middle Miocene flexuralmargin migration of the no marine Llanos foreland basin of Colombia. CT\&F Ciencia, Tecnología y Futuro. 3 (3): 141-160.

Bayona, G., Cortés, M., Jaramillo, C., Ojeda, G., Aristizábal, J., Reyes-Harker, A. (2008). An integrated analysis of an orogen-sedimentary basin pair: Latest Cretaceous- 
Cenozoic evolution of the linked Eastern Cordillera orogen and the Llanos foreland basin of Colombia. Geological Society of America Bulletin. 120: 1171-1197.

Bayona, G., Montenegro, O., Cardona, A., Jaramillo, C., Lamus, F., Morón, S., Quiroz, L., Ruiz, M. C., Valencia, V., Parra, M., Stockli, D. (2010). Estratigrafía, procedencia, subsidencia y exhumación de las unidades paleógenas en el Sinclinal de Usme, sur de la zona axial de la Cordillera Oriental, Geología Colombiana. 35: 5-35.

Bayona, G., Montes, C., Cardona, A., Jaramillo, C., Ojeda, G., Valencia, V. (2011). Intraplate subsidence and basin filling adjacent to an oceanic arc-continental collision; a case from the southern Caribbean-South America plate margin. Basin Research. 23: 403-422. Doi:10.1111/j.13652117.2010.00495.x

Bayona, G., Cardona, A., Jaramillo, C., Mora, A., Montes, C., Valencia, V., Ayala, C., Montenegro, O., Ibáñez, M. (2012). Early Paleogene magmatism in the northern Andes: Insights on the effects of Oceanic Plateau-continent convergence. Earth and Planetary Science Letters. 331332: 97-111. Doi: 10.1016/j.eps1.2012.03.015

Bayona, G., Cardona, A., Jaramillo, C., Mora, A., Montes, C., Caballero, V., Mahecha, H., Lamus, F., Montenegro, O., Jiménez, G., Mesa, A., Valencia, V. (2013). Onset of fault reactivation in the Eastern Cordillera of Colombia and proximal Llanos basin; response to Caribbean South American collision in early Palaeogene time. In: Nemčok, M., Mora, A.R., and Cosgrove, J.W. (Eds), Thick-Skin-Dominated Orogens: From Initial Inversion to Full Accretion. Geological Society of London, Special Publication 377, p. 285-314. Doi: 10.1144/SP377.5

Bayona, G., Cardona, A., Téllez, G., Garzón, A., Pinzón, D., Méndez, J., Ramírez, C., Rueda, M. (2015). Magmatismo Paleoceno-Eoceno Temprano(?) en la Cuenca proximal de los Llanos, XV Congreso Colombiano de Geología, Bucaramanga, Colombia, p. 560-563.

Bermúdez, M., Kohn, B.P., van der Beek, P.A., Bernet, M., O'Sullivan, P.B., Shagam, R. (2010). Spatial and temporal patterns of exhumation across the Venezuela Andes: Implications for Cenozoic Caribbean geodynamics. Tectonics. 29: TC5009. Doi:10.1029/2009TC002635, 2010

Bustamante, C., Archanjo, C., Cardona, A., Valencia, V., Vervoort, J. (2016). Late Jurassic to Early Cretaceous plutonism in the Colombian Andes: A record of long-term arc maturity. Geological Society of America Bulletin. 128 (11-12): 1762-1779. Doi: 10.1130/B31307.1

Bustamante, C., Cardona, A., Archanjo, C.J., Bayona, G., Lara, M., Valencia, V. (2017). Geochemistry and isotopic signatures of Paleogene plutonic and detrital rocks of the Northern Andes of Colombia: A record of post-collisional arc magmatism. Lithos. 277: 199-209. Doi: 10.1016/j. lithos.2016.11.025

Cardona, A., Valencia V. A., Bayona, G., Duque, J., Ducea, M., Gerhels, G., Jaramillo C., Montes, C., Ojeda, G., Ruiz, J. (2011). Early subduction orogeny in the Northern Andes: Turonian to Eocene magmatic and provenance record in the Santa Marta Massif and Rancheria Basin, Northern Colombia. Terranova. 23: 26-34.

Cardona, A., Weber, M., Valencia, V., Bustamante, C., Montes, C., Cordani, U., Muñoz, C.M. (2014). Geochronology and geochemistry of the Parashi granitoid, NE Colombia:
Tectonic implication of short-lived Early Eocene plutonism along the SE Caribbean margin. Journal of South American Earth Sciences. 50: 75-92.

Catuneanu, O. (2018). First-order foreland cycles: Interplay of flexural tectonics, dynamic loading, and sedimentation. Journal of Geodynamics. Doi: 10.1016/j.jog.2018.03.001

Carroll, A. R. (2017). Xenoconformities and the stratigraphic record of paleoenvironmental change. Geology 45: 639642. Doi:10.1130/G38952.1

Cediel, F., Shaw, R.P., Cáceres, C. (2003). Tectonic assembly of the Northern Andean Block. In: C. Bartolini, R.T. Buffler, J. Blickwede, (editors). The Circum-Gulf of México and the Caribbean: Hydrocarbon habitats, basin formation, and plate tectonics. AAPG Memoir. 79: 815-848.

Cohen, K.M., Finney, S.C., Gibbard, P.L., Fan, J.X. (2013, updated in 2018). The ICS International Chronostratigraphic Chart. Episodes. 36: 199-204.

Cooper, M. A., Addison, F. T., Álvarez, R., Coral, M., Graham, R. H., Hayward, A. B., Howe, S., Martínez, J., Naar, J., Peñas, R., Pulham, A. J., Taborda, A. (1995). Basin development and tectonic history of the Llanos basin, Eastern Cordillera, and Middle Magdalena Valley, Colombia. American Association of Petroleum Geologists Bulletin. 79: 1421-1443.

Cortés, M., Angelier, J., Colletta, B. (2005). Paleostress evolution of the northern Andes (Eastern Cordillera of Colombia): Implications on plate kinematics of the South Caribbean region. Tectonics. 24: TC1008. Doi: 10.1029/ 2003TC001551

Díaz, L. (1994). Distribución de las facies siliciclásticas correspondientes a la Formación Arenisca Tierna y equivalentes en el Valle Superior del Magdalena. En: Etayo-Serna, F. (ed). Estudios Geológicos del Valle Superior del Magdalena, Universidad Nacional de Colombia, p. IV1-15.

Erlich, R.N., Villamil, T., Keens-Dumas, J. (2003). Controls on the deposition of Upper Cretaceous organic carbonrich rocks from Costa Rica to Suriname, in Bartolini, C., Buffler, R., and Blickwede, J., eds., The Circum-Gulf of Mexico and the Caribbean: Hydrocarbon Habitats, Basin Formation and Plate Tectonics, American Association of Petroleum Geologists Memoir. 79: 1-45.

Etayo, F., Renzoni, G., Barrero, D. (1976). Contornos sucesivos del mar Cretácico en Colombia. Primer Congreso Colombiano de Geología, Memoria., Bogotá, p. 217-252.

Fabre, A., Osorio, M., Vargas, R., Etayo, F. (1985). Geología de la plancha 137 - Cocuy. Escala 1:100.000. Digitalizado y estandarizado en el año 2009. Servicio Geológico Colombiano (antiguo INGEOMINAS), Bogotá, Colombia.

Goméz, E., Jordan, T.E., Allmendinger., Hegarty, K., Kelley, S., Heizler, M. (2003). Controls on architecture of the Late Cretaceous to Cenozoic southern Middle Magdalena Valley Basin, Colombia. GSA Bulletin. 115: 131-147.

Goméz, E., Jordan, T.E., Allmendinger., Hegarty, K., Kelley, S., Heizler, M. (2005). Syntectonic Cenozoic sedimentation in the northern middle Magdalena Valley Basin of Colombia and implications for exhumation of the Northern Andes. GSA Bulletin. 117: 547-56. Doi: 10.1130/B25454.1

Guerrero, J., Sarmiento, G. (1996). Estratigrafía Física, Palinológica, Sedimentológica y Secuencial del Cretácico Superior y Paleoceno del Piedemonte Llanero. Implicaciones en Exploración Petrolera. Geología Colombiana. 20: 3-66. 
Guerrero, J., Sarmiento, G., Navarrete, R. (2000). The stratigraphy of the W Side of the Cretaceous Colombian Basin in the upper Magdalena Valley. Reevaluation of Selected Areas and Type Localities including Aipe, Guaduas, Ortega, and Piedras. Geología Colombiana. 25: 45-110.

Gurnis, M. (1992). Rapid continental subsidence following the initiation and evolution of subduction. Science. 255: 15561558.

Haq, B.U. (2014), Cretaceous eustasy reconsidered: Global and Planetary Change. 113: 44-58. Doi:10.1016/j.gloplacha. 2013.12.007

Hoorn, C., Guerrero, J., Sarmiento, G.A., Lorente, M.A. (1995). Andean tectonics as a cause for changing drainage patterns in Miocene northern South America: Geology. 23: 237-240.

Horton, B.K. (2018). Sedimentary record of Andean mountain building. Earth-Science reviews. 178: 279-309.

Hu, X., Wagreich, M., Yilmaz, I.O. (2012). Marine Rapid Environmental/Climatic Change in the Cretaceous Greenhouse World. Cretaceous Research. 38: 1-6.

Jaramillo, J.S., Cardona, A., León, S., Valencia, V., Vinasco, C. (2017). Geochemistry and geochronology from Cretaceous magmatic and sedimentary rocks at 6_350 N, western flank of the Central cordillera (Colombian Andes): Magmatic record of arc growth and collision. Journal of South American Earth Sciences. 76: 460-481.

Jiménez, G., Rico, J., Bayona, G., Montes, C., Rosero, A., Sierra, D. (2012). Analysis of curved folds and fault/fold terminations in the southern Upper Magdalena Valley of Colombia. Special Edition on Tectonic and climatic shaping of the northern Andes and southern Caribbean margin (Edited by G. Bayona., B. Horton., A. Reyes-Harker). Journal of South America Earth Sciences. 39: 184-201.

Lamus, F., Bayona, G., Cardona, A., Mora, A. (2013). Procedencia de las unidades Cenozoicas del Sinclinal de Guaduas: implicación en la evolución tectónica del sur del Valle del Magdalena y orógenos adyacentes. Boletín de Geología de la UIS. 35: 17-42.

Mann, P., Escalona, A, Castillo, M. V. (2006). Regional geologic and tectonic setting of the Maracaibo supergiant basin, western Venezuela. AAPG Bulletin. 90: 445-477. Doi: 10.1306/10110505031

Martínez, J.I, Hernández, R. (1992). Evolution and drowning of the Late Cretaceous Venezuela carbonate platform. Journal of South American Earth Science. 5 (2): 197-210.

Mitrovica, J. X., Beaumont, C., Jarvis, G.T. (1989). Tilting of continental interiors by the dynamical effects of subduction. Tectonics. 8: 1079-1094.

Montaño, P., Nova, G., Bayona, G., Mahecha, H., Ayala, C., Jaramillo, C., de la Parra, F. (2016). Análisis de secuencias en sucesiones sedimentarias de grano fino: un ejemplo de la Formación Umir y base de la Formación Lisama, en el sector de Simacota (Santander, Colombia). Boletín de Geología de la Universidad Industrial de Santander. 38: 51-72.

Montes, C., P.A. Restrepo-Pace, R.D. Hatcher Jr. (2003). Three-dimensional structure and kinematics of the Piedras Girardot fold belt: Surface expression of transpressional deformation in the northern Andes, in C. Bartolini, R.T. Buffler, and J. Blickwede, eds., The Circum-Gulf of Mexico and the Caribbean: Hydrocarbon habitats, basin formation, and plate tectonics: AAPG Memoir. 79: 849-873.
Montgomery, R.D. \& Dietrich, W.E. (1992). Channel initiation and the problem of landscape scale. Science. 255: 826-830.

Mora, A., Venegas, D., Vergara, L. (1998). Estratigrafía del Cretácico Superior y Terciario Inferior en el Sector Norte de la Cuenca del Putumayo, Departamento del Caquetá, Colombia. Geología Colombiana. 23: 31-77.

Mora, A., Reyes-Harker, A., Rodríguez, G., Tesón, E., RamírezArias, J.C., Parra, M., Caballero, V., Mora, J.P., Quintero, I., Valencia, V., Ibáñez, M., Horton, B., Stokli, D. (2013). Inversion tectonics under increasing rates of shortening and sedimentation: Cenozoic example from the Eastern Cordillera of Colombia. In: Nemčok, M., Mora, A.R., and Cosgrove, J.W. (Eds), Thick-Skin-Dominated Orogens: From Initial Inversion to Full Accretion. Journal of the Geological Society of London, Special Publication. 377: 411-442.

Mora, A., Casallas, W., Ketcham, R.A., Gómez, D., Parra, M., Namson, J., Stockli, D., Almedral, A., Robles, W., Ghorbal, B. (2015). Kinematic restoration of contractional basement structures using thermokinematic models: A key tool for petroleum system modeling. AAPG Bulletin. 99 (8): 1575-1598.

Moreno, J., Velásquez, M. (1993). Estratigrafía y tectónica en los alrededores de Nunchía, departamento de Casanare, Colombia. Tesis de grado \#325, Universidad Nacional de Colombia, Bogotá.

Montenegro, G., Barragán, M. (2011). Caguán and Putumayo Basin. In: F. Cediel, (editor), Petroleum Geology of Colombia. 4: 127.

Montenegro, O., Bayona, G., Cardona, A., Restrepo-Moreno, S., Ojeda, C., Ayala, C. (2012). Procedencia de las unidades paleógenas de la cuenca del Catatumbo y su comparación con las cuencas adyacentes: relación con la convergencia de la placa Caribe. Geología Colombiana. 37 (2): 123-151.

Nie, J., Horton, B.K., Saylor, J.E., Mora, A., Mange, M., Garzione, C.N., Basu, A., Moreno, C.J., Caballero, V., Parra, M. (2012). Earth- Science Reviews. 110: 111- 126. Doi: 10.1016/j.earscirev.2011.11.002

Parra, M., Mora, A., Jaramillo, C., Torres, V., Zeilinger, G, Strecker, M. R. (2010). Tectonic controls on Cenozoic foreland basin development in the north-eastern Andes, Colombia. Basin Research. Doi: 10.1111/j.1365-2117.2009. 00459.x

Parra, M., Mora, A., López, C., Rojas, L. E., Horton, B. K. (2012). Detecting earliest shortening and deformation advance in thrust belt hinterlands: Example from the Colombian Andes. Geology. 40: 175-178.

Patarroyo, G.D., Torres, G.A., Rincón, D.A., Cárdenas, C.P., Márquez, R.E. (2017). Bioestratigrafía e inferencias paleoambientales de las asociaciones de foraminíferos en las formaciones cretácicas La Luna-Colón (Cuenca del Catatumbo, Colombia). Boletín de Geología, 39 (3): 25-40.

Pedraza, P., Ramírez, Y. (2011). Petroleum Geology of Colombia Catatumbo Basin. F. Cediel (editor), F. Colmenares (coeditor). Fondo Editorial universidad EAFIT. V. 5.

Pérez, G., Salazar, A. (1978). Estratigrafía y facies del Grupo Guadalupe. Geología Colombiana. 10: 7-85.

Pindell, J., Kennan, L., Stanek, K.P., Maresch, W.V., Draper, G. (2006). Foundations of Gulf of México and Caribbean evolution: Eight controversies resolved. Geological Acta. 4 (1-2): 303-341. 
Pindell, J.L., Kennan, L. (2009). Tectonic evolution of the Gulf of México, Caribbean and northern South America in the mantle reference frame: An update. Geological Society, London, special publication. 328: 1-55.

Restrepo-Pace, P. A., Colmenares, F., Higuera, C., Mayorga. M. (2004). A fold and-thrust belt along the western flank of the Eastern Cordillera of Colombia - Style, kinematics, and timing constraints derived from seismic data and detailed surface mapping, in K. R. McClay, ed., Thrust tectonics and hydrocarbon systems: AAPG Memoir. 82: 598-613.

Reyes- Harker, A., Ruiz- Valdivieso, C.F., Mora, A., RamírezArias, J.C., Rodríguez, G., Parra, F., Caballero, V., Parra, M., Moreno, N., Horton, B.K., Saylor, J.E., Silva, A., Valencia, V., Stoddi, D., Blanco, V. (2014). Cenozoic paleogeography of the Andean foreland and retroarc hinterland of Colombia. AAPG Bulletin. 9 (8): 1407- 1453. Doi: $10.1306 / 06181411110$

Royero, J.M. (1998). Geología de la plancha 111 - Toledo: Memoria Explicativa. Ingeominas. Informe 2308a.

Sánchez, J., Horton, B.K., Tesón, E., Mora, A., Ketcham, R.A, Stockli, D.F. (2012). Kinematic evolution of Andean foldthrust structures along the boundary between the Eastern cordillera and Middle Magdalena Valley basin, Colombia. Tectonics. 31: TC3008. Doi: 10.1029/2011TC003089

Sarmiento, G. (1992). Estratigrafía y medios de depósito de la Formación Guaduas. Ingeominas, Bogotá, Boletín Geológico. 32 (1): 3-44.

Sarmiento L. F., ANH. Petroleum Geology of Colombia, Llanos basin. F. Cediel, (editor), G.Y Ojeda, (co-editor). Fondo editorial Universidad EAFIT. v. 9.

Saylor, J.E., Horton, B.K., Nie, J., Corredor, J., Mora, A. (2011). Evaluating foreland basin partitioning in the northern Andes using Cenozoic fill of the Floresta basin, Eastern cordillera, Colombia. Basin Research. 23: 377-402. Doi: 10.1111/j.1365-2117.2010.00493.x

Schumm, S.A., Dumont, J.F., Holbrook, J.M. (2000). Active tectonics and alluvial rivers. Cambridge, United Kingdom: Cambridge University Press, 276 p.

Spikings, R., Cochrane, R., Villagómez, D., Van der Lelij, R., Vallejo, C., Winkler, W., Beate, B. (2015). The geological history of northwestern South America: From Pangaea to the early collision of the Caribbean Large Igneous Province (290- $75 \mathrm{Ma}$ ). Gondwana Research. 27: 95-139. Doi: 10.1016/j.gr.2014.06.004
Servicio Geológico Colombiano. (2015). Elaboración de la cartografía geológica de un conjunto de planchas a escala 1:100.000 ubicadas en cuatro bloques del territorio nacional identificados por el Servicio Geológico Colombiano grupo 2: zonas Sur A y sur B. Memoria explicativa, geología de la plancha 304 La Uribe. Contrato $\mathrm{N}^{\circ} 512$.

Van Der Lelij, R. (2013). Reconstructing north-western Gondwana with implications for the evolution of the Iapetus and Rheic Oceans: A geochronological, thermochronological and geochemical study. Doctorade thesis, University of Genève, 248 p. Genève. Doi: 10.13097/archive-ouverte/ unige: 31653

Veloza, G. E., Mora, A., Freitas, M., Mantilla, M. (2008). Dislocación de facies en el tope de la secuencia Cretácica de la subcuenca de Neiva, Valle Superior del Magdalena y sus implicaciones en el modelo estratigráfico secuencial colombiano. Boletín de Geología. 30 (1): 29-44.

Vergara, L., Rodríguez, G. (1997). The Upper Cretaceous and Lower Paleocene of the Eastern Bogotá Plateau and Llanos Thrustbelt, Colombia: Alternative appraisal to the nomenclature and sequence stratigraphy. Geología Colombiana. 22: 51-79.

Villagómez, D., Spikings, R. (2013). Thermochronology and tectonics of the Central and Western Cordilleras of Colombia- Early Cretaceous-Tertiary evolution of the Northern Andes. Lithos. 160-161: 228-249.

Villamil, T., Arango, C. (1998). Integrated stratigraphy of latest Cenomanian and early Turonian facies of Colombia. Paleogeographic evolution and non-glacial eustasy, Northern South America, SEPM Spec. Publ. 58: 129-159.

Villamil, T. (1999). Campanian- Miocene tectonostratigraphy depocenter evolution and basin development of Colombia and western Venezuela. Paleogeography, Paleoclimatology, Paleoecology, 153 (1-4): 239-275.

Weber, M., Cardona, A., Valencia, V., García-Casco, A., Tobón, M., Zapata, S. (2010). U/Pb detrital zircon provenance from Late Cretaceous metamorphic units of the Guajira Peninsula, Colombia: Tectonic implications on the collision be- tween the Caribbean arc and the South American margin. Journal of South American Earth Sciences. 29: 805-816.

Yepes, O. (2001). Dinoflagellates from the upper CampanianMaastrichtian of Colombia and western Venezuela: Biostratigraphic and sequence stratigraphic implications. Submitted to the Office of Graduate studies of Texas A\&M University, December 2001. 